\title{
Celpe-Bras e CELU: possíveis inter-relações linguísticas, interculturais e multiterritoriais
}

\author{
Fernanda Ricardo Campos \\ CEFET-MG
}

\author{
Ronaldo Tavares Gomes \\ CEFET-MG
}

\begin{abstract}
Resumo
Este artigo propõe investigar os construtos dos testes de proficiência CELPE-BRAS (Certificado de Proficiência em Língua Portuguesa para Estrangeiro - Brasil) e CELU (Certificado de Español: Lengua y Uso - Argentina), verificando não só as suas convergências e possíveis divergências, mas, sobretudo, as possibilidades de comunicação e compreensão intercultural que ambos os testes possam proporcionar a brasileiros e argentinos. O CELPE-BRAS e o CELU são dois exames de proficiência oficiais, promovidos e realizados por países em um mesmo continente e fronteiriços, cujo construto, formatos e abordagens de avaliação têm uma relação muito próxima. Nesse sentido, é importante saber como se fundamentam esses exames, quais são os seus construtos e como eles se relacionam; assim poderá ser possível estabelecer uma análise comparativa e verificar quais os reflexos que se podem depreender deste estudo, a fim de que se possa conceber, de forma mais contemporânea, uma melhor compreensão desses dois testes de proficiência.
\end{abstract}

Palavras-Chave: Avaliação; construto; Celpe-bras; Celu; plurilinguismo.

\begin{abstract}
This article proposes to investigate the constructs of CELPE-BRAS (Certificate of Proficiency in Portuguese for Foreigners - Brazil) and CELU (Certificate of Spanish: Language and Usage - Argentina) proficiency tests, in order to verify not only their convergences and possible divergences, but, above all, the possibilities of communication and intercultural understanding that both tests can provide for Brazilians and Argentines. CELPE-BRAS and CELU are two official proficiency exams promoted and carried out by countries that share the same continent and borders, whose construct, formats and approach to evaluation are closely related. In this sense, it is important to know what the bases are for these exams, what their constructs are, and how they relate to each other. Answers to these questions may help to establish a comparative analysis and check what can be drawn from this study, so that there can be gained a more contemporary and fuller understanding of these two proficiency tests.
\end{abstract}

Keywords: Assessment; Construct; Celpe-bras; Celu; Multilingualism 


\section{INTRODUÇÃO}

A proposta deste artigo é fazer um estudo comparativo, a fim de que se possa conceber, de forma contemporânea, uma melhor compreensão dos testes de proficiência CELPE-BRAS (Certificado de Proficiência em Língua Portuguesa para Estrangeiro - Brasil) e CELU (Certificado de Español: Lengua y Uso - Argentina) e analisar quais são as possibilidades linguísticas, interculturais e multiterritoriais (OLIVEIRA, 2013) que ambos venham proporcionar aos dois países em questão.

Os instrumentos de testagem de segunda língua podem contribuir para um diálogo e uma cooperação entre o Português e o Espanhol, no sentido de atestarem uma proficiência linguística, mas também de propiciarem uma múltipla inserção territorial e uma diminuição das distâncias entre essas duas nações (HAESBAERT, 2004).

Sendo assim, ao se pensar nos diversos efeitos retroativos, gerados pelo preparo para esses testes, e considerando-se seus objetivos e construtos, é possível verificar-se que ambos podem promover um diálogo essencial para o fortalecimento da relação e da comunicação entre essas línguas e culturas entre ambas e o mundo (SCARAMUCCI, 2003).

\section{OS EXAMES}

Como os exames que avaliam a proficiência em geral, o principal objetivo do Celpe-Bras (Certificado de Proficiência em Língua Portuguesa para Estrangeiro - Brasil) e CELU (Certificado de Español: Lengua y Uso - Argentina) é avaliar a proficiência de quem precisa usar o português ou o espanhol, principalmente, para aqueles que precisam estudar/trabalhar no Brasil ou na Argentina.

O Celpe-Bras é o único exame de proficiência em língua portuguesa como língua estrangeira que possibilita a certificação para estrangeiros reconhecido no Brasil. Foi desenvolvido pelo Ministério da Educação (MEC) e é aplicado aqui e em outros países com o apoio do Ministério das Relações Exteriores (MRE). É aceito em empresas e instituições de ensino internacionais como comprovação de competência na língua portuguesa. No Brasil, é exigido por universidades para ingresso em cursos de graduação e em programas de pósgraduação, bem como para validação de diplomas de profissionais estrangeiros que pretendem trabalhar no país. 
O CELU é um exame que certifica o espanhol como língua estrangeira. Pode ser obtido por pessoas, cuja primeira língua não é o espanhol e que queiram validar sua capacidade de usar o idioma para o âmbito de trabalho e estudo. O CELU é o único exame reconhecido oficialmente pelo Ministério de Educação e pelo Ministério de Relações Exteriores e Culto da República Argentina, sendo também reconhecido pelos governos do Brasil, China e Itália.

O exame Celpe-Bras é composto por duas partes, uma escrita e uma oral. A parte escrita dura três horas e possui quatro tarefas, duas baseadas em compreensão oral e duas em leitura. A parte oral dura 20 minutos e é composta por uma conversa sobre os interesses do candidato e sobre tópicos do cotidiano. Os interesses particulares do examinando são definidos a partir de um questionário preenchido no ato da inscrição e, no exame, são abordados numa conversa inicial que se define por quebra gelo, que dura cerca de 5 minutos. Os 15 minutos restantes são sobre tópicos do cotidiano e de interesse geral, com base em três Elementos Provocadores diferentes, com a duração de 5 minutos cada um. O Celpe-Bras certifica quatro níveis de proficiência: Intermediário, Intermediário Superior, Avançado e Avançado Superior.

Da mesma forma, o exame CELU é composto por duas partes em que o candidato tem a oportunidade de mostrar seu desempenho por meio da escrita e da oralidade. A primeira parte escrita - tem duração de três horas. $\mathrm{O}$ candidato deve elaborar quatro textos para responder a distintas situações por meio de tarefas. A segunda parte - oral - dura, aproximadamente, 20 minutos. $\mathrm{O}$ candidato conversa com o avaliador, com base em um texto autêntico breve (um anúncio publicitário, uma notícia, um cartaz, entre outros). A conversa pode ter as características de uma entrevista ou de um diálogo, em que pode haver exposição de ideias ou de dados, relatos de experiências próprias do candidato, discussão de opiniões etc. Em seguida, é proposta ao candidato uma simulação de situações cotidianas (encenada entre ele e o avaliador), a partir das instruções e dos temas propostos em uma lâmina. O CELU certifica dois níveis de proficiência: Intermediário e Avançado.

O Celpe-Bras e o CELU, ao centrarem-se no enfoque por tarefas, fazem com que seus exames tenham uma amplitude maior que um teste de conhecimentos gramaticais. O que se está testando, na verdade, é se o examinando possui a proficiência linguística, o conhecimento cultural, se ele sabe fazer uso de práticas consideradas culturalmente adequadas para realizar tarefas específicas, tais como comprar algo, marcar uma consulta médica, reclamar sobre um produto, persuadir alguém, expor suas ideias. De acordo com Schlatter, Scaramucci, Prati e Acuna (2008), isso é compatível com uma educação política, em que o objetivo é o de preparar 
cidadãos bilíngues de acordo com suas necessidades e práticas sociais, promovendo, assim, a integração de regiões. Segundo as mesmas autoras, o Celpe-Bras e o CELU medem a capacidade do falante "em agir no mundo", preparando-o de acordo com suas necessidades dentro da esfera social em que vivenciará. Nesse sentido, é possível perceber também a contribuição desses exames para uma integração de seus candidatos a múltiplas territorialidades.

Há ainda que se considerar o efeito retroativo dos exames, partindo do pressuposto de que avaliações em grande escala têm impactos sociais. Schlatter, Scaramucci, Prati e Acuna (2008) reforçam ainda que um dos objetivos do exame é orientar as práticas de ensino de Espanhol e de Português, como língua estrangeira, na medida em que, tradicionalmente, o ensino de idiomas tem sido pautado apenas em materiais focalizados, no geral, em exercícios de gramática, sintaxe e vocabulário, com atividades, não muito bem exploradas, de leitura e de escrita. Dessa forma, esses exames acabam provocando um efeito retroativo na confecção do material didático existente no mercado, além de fomentarem uma postura diferenciada no ensino-aprendizagem de línguas estrangeiras. Baseando-se no construto dos dois exames, é possível verificar uma urgente mudança nas práticas dos professores em sala, que acabam se adequando, também, a esses objetivos propostos pelo Celpe-Bras e pelo CELU.

\section{A PERSPECTIVA DA SEGUNDA LÍNGUA NO MERCOSUL.}

O Mercosul (Mercado Comum do Sul) foi criado em 1991, tendo como um dos principais objetivos acordados pelos seus membros promover ações destinadas ao desenvolvimento e integração do cidadão e melhorar padrões de educação. Alguns interesses comuns e iniciativas conjuntas na área educacional, cultural e econômica conduziram a ações e a oportunidades para uma relação mais estreita entre os países da América do Sul. Sua criação tem promovido a construção de um ambiente bilíngue português-espanhol, impulsionando iniciativas ligadas à cooperação educacional, científica e tecnológica em ambas as línguas. Um desses indícios é o próprio exame Celpe-Bras que serviu como base de elaboração para o CELU, fruto da colaboração entre a comissão acadêmica argentina, responsável pelo exame, e a comissão técnica do Celpe-Bras, utilizando a mesma tecnologia do exame brasileiro (CARVALHO; SCHLATTER, 2011). Segundo Prati (2007), um acordo de reconhecimento dos dois exames, firmado em 2004, só tem a somar a essa relação, não somente entre Brasil e 
Argentina, mas também entre Uruguai e Paraguai, ao reunir universidades nacionais, intercâmbio de professores, além de programas de formação e avaliação desses idiomas como segunda língua, tanto o Português como o Espanhol. A autora ainda acrescenta a validade do exame, pois é reconhecido por seu Estado, e isso agrega valor às línguas, além de importantes avanços na educação de cada país, como o crescimento de cursos de capacitação para professores, novos programas de pós-graduação, elaboração de material didático e pesquisa. Esse reconhecimento daria a esses países não apenas a possibilidade de crescimento pessoal, mas também proporcionaria uma integração cultural, capaz de promover a interação com outras culturas, em benefício de uma sociedade integrada. Nessa perspectiva, é possível citar iniciativas que já vêm dando resultado, como o Programa Alrededor del CELU, cujo objetivo é reunir esforços de ambos os lados, em uma cooperação para difundi-lo no Brasil, no sentido de explicitar as concepções do exame para os docentes de espanhol como língua estrangeira no nosso território brasileiro. Esse projeto visa a uma maior contribuição entre Universidades e Institutos Brasileiros e o Consórcio Interuniversitário Argentino. (RODRIGUES, 2009).

\section{A QUESTÃO DA INTERCULTURALIDADE}

O ensino de línguas estrangeiras, em um mundo globalizado, carece de reflexões que devem ser a base para uma eficiente inserção de um estudante no contexto comunicativo de outro idioma. Um processo de comunicação efetivo entre falantes de línguas diferentes não pode pressupor apenas o conhecimento das suas estruturas linguísticas. Além do importante conhecimento e estudo do arcabouço fonológico, morfossintático, lexical, ortográfico, discursivo de qualquer idioma, é preciso entender ainda os processos de contextualização, por meio dos quais se possa fazer entender e ser entendido. Há situações de interlocução inerentes a determinados países ou regiões em que são empregadas, uma vez que determinados valores, crenças e comportamentos delineiam comunidades de falantes. A compreensão desses componentes culturais é a base para que um aprendiz de segunda língua possa se comunicar de forma eficiente e sem enfrentar alguns ruídos em situações comunicacionais. Quando se fala em conhecimentos culturais não é possível ater-se a questões superficiais e de conhecimento popular que, via de regra, acabam por se tornar estereótipos. Essas generalizações que as pessoas acabam fazendo sobre determinados comportamentos ou características de outros povos não são suficientes para que se possa compreender e usar um segundo idioma de forma a 
se comunicar eficientemente em certas situações. A ideia do Modelo de Iceberg, proposta por Cassiano, traduz bem esta questão, quando diz que "um iceberg nos permite diferenciar entre os elementos de uma cultura que são reconhecidos facilmente (a parte do iceberg que fica acima da água) e os elementos que não são reconhecidos com tanta facilidade (a parte do iceberg abaixo da água)" (CASSIANO, 2013, p.3).

Para se pensar em um uso eficiente de uma segunda língua, é preciso pesquisa e esforço, não só no que diz respeito às quatro habilidades comunicativas, mas também no sentido de se ampliar a visão sistêmica de ensino-aprendizagem, a partir de uma ótica aprofundada, ou seja, por meio da perspectiva intercultural. A diversidade é o principal desafio a ser vencido por um nativo que deseja imergir-se em outro idioma. Nenhuma língua e nenhum povo são imutáveis e permanentes. A história do Brasil e da Argentina reflete bem essa premissa. Portugal e Espanha deixaram como herança não só a Língua Portuguesa e a Língua Espanhola a esses países, mas também uma diversidade de costumes, hábitos, valores, crenças e comportamentos que, a estes, foram incorporados inúmeros outros elementos e substratos nativos, além daqueles que se incorporaram no decorrer do tempo. Contudo, foi por meio desses encontros, desencontros e diferenças que se aglutinaram uma série de manifestações culturais que refletem hoje as idiossincrasias de cada nação. Como diz Rosário Farmhouse, diretora da Revista B-i (agosto, 2010), Alta Comissária para a Imigração e Diálogo Intercultural - ACIDI, "enriquecer no encontro das diferenças é o princípio da Interculturalidade".

Segundo Barroso \& Dandrea, "una lengua no puede pensarse independientemente de la cultura que (la) soporta" (BARROSO \& DANDREA, 2011, p.1), pois o uso eficiente de um idioma está diretamente relacionado com a capacidade do falante em conseguir concatenar as estruturas linguísticas aos devidos contextos socioculturais de seus nativos. Ambos os autores corroboram com essa visão quando dizem ainda que "lengua y cultura son dos dimensiones profundamente imbricadas que no pueden enseñarse - una $y / u$ otra - si no es a partir de su articulación reflexiva" ${ }^{2}$.

Mendes reforça essa questão da importância que a interculturalidade representa para o aprendiz de outro idioma, quando afirma que “(...) aprender uma língua, aprendendo uma cultura, significa mais do que uma simples eleição de enfoques metodológicos, é, antes de tudo,

\footnotetext{
${ }^{1}$ Tradução livre: não se pode pensar uma língua independentemente da cultura que (a) suporta.

${ }^{2}$ Tradução livre: língua e cultura são duas dimensões profundamente imbricadas que não podem ensinar-se - uma e/ou outra - si não for a partir de sua articulação reflexiva.
} 
uma forma alternativa de construção de processo de ensino-aprendizagem de línguas" (MENDES, 2002, p. 186). Ao aprender sobre outra cultura, ao vivenciá-la, o estudante de qualquer segunda língua acaba tornando-se parte daquilo, ele passa a ter acesso a informações e a curiosidades até então desconhecidas. Apreende não apenas a língua, mas tudo o que implica em sua aprendizagem, seu entendimento. Pensar o aprendizado de outro idioma por esse ângulo resulta em um processo de aquisição e uso de uma segunda língua mais facilitado, inovador e instigante para o aluno.

Relativamente ao Brasil e à Argentina, no processo de ensino-aprendizagem de uma segunda língua - o Português, o Espanhol e vice-versa -, é possível perceber como é essencial o conhecimento das semelhanças e das diferenças entre esses dois países, no que diz respeito à diversidade, ao comportamento, aos costumes, aos hábitos de ambos os povos. De acordo com Delia, para que se possa imbuir-se dessa perspectiva intercultural, há que se ter em conta três aspectos: "la enseñanza de la cultura del otro, la superación de barreras personales y transaccionales presentes en las dos culturas, y la relación entre el aprendizaje de esa cultura y el aprendizaje de la segunda lengua" ${ }^{3}$ (DELIA, 2008, p. 1). Cumprimentar-se no Brasil e na Argentina entre dois amigos do sexo masculino, por exemplo, é algo que transcende questões como o simples uso de certas expressões linguísticas do tipo: ¡Hola!, ¿qué tal? ou Oi, como vai?, uma vez que os amigos argentinos se beijam no rosto, coisa que, em geral, para um brasileiro é algo estranho entre amigos do mesmo sexo. Outro exemplo é a palavra espanhola boludo $^{4}$, usada na Argentina. Ela representa uma expressão intensamente bipolar que pode gerar ódios ou simpatias pela quantidade de coisas que transmite e simboliza, não só por situações de contextos, mas também de entonação. Enfim, há uma série de exemplos tanto na Língua Portuguesa quanto na Espanhola que poderiam ilustrar a importância do conhecimento intercultural para o uso de ambos os idiomas, justificativas mais que justas para se fundamentar a importância do âmbito cultural no aprendizado destes ou de quaisquer idiomas.

Reforçando essa premissa, o Protocolo entre o Ministério da Educação, Ciência e Tecnologia da República Argentina e o Ministério de Educação da República Federativa do Brasil para a Promoção do Ensino do Espanhol e do Português como Segundas Línguas, de 30

\footnotetext{
${ }^{3}$ Tradução livre: o ensino da cultura do outro, a superação de barreiras pessoais e transacionais presentes nas duas culturas e a relação entre a aprendizagem dessa cultura e a aprendizagem da segunda língua.

4 "Boludo" pode ser aquele que tem testículos grandes, mas, geralmente, é usado para expressar que uma pessoa é idiota, imbecil, tonta. Por outro lado, dependendo do nível de intimidade entre os interlocutores, é possível chamar uma outra pessoa por esse nome, simplesmente como um vocativo afetivo de um amigo para outro. Ela pode se flexionar em gênero e grau.
} 
de novembro de 2005, já sinalizou que, além da questão linguística, a importância da interculturalidade também é fundamental para o conhecimento recíproco dos seus idiomas oficiais. O documento reafirma ainda que a educação deve ser o espaço a partir do qual se promove e constrói uma consciência favorável para a integração, valorizando a diversidade e a importância dos códigos interculturais e linguísticos de cada país.

\section{A AVALIAÇÃo COMO FATOR DE PROPULSÃO INTERCULTURAL ENTRE BRASIL E ARGENTINA}

Não seria possível pensar em avaliação de exames de proficiência sem se pressupor a interlocução. No caso, quando se fala em interlocução, é preciso entendê-la sob um panorama mais abrangente. A ideia não seria apenas considerar que ela se dê apenas nos âmbitos linguístico e estrutural. Há que se considerar, nesse processo, fatores extra linguísticos fundamentais para se propor a inserção de falantes de um idioma no universo de uma segunda língua. Nesse sentido, a questão intercultural deve ocupar uma relevância estratégica no processo de ensino aprendizagem de um idioma, desde que se possa atentar para o fato de que a cultura não se faz aceder para o outro sem se partir da perspectiva de que a cultura do outro também é relevante para uma compreensão mais ampla da primeira.

Dessa forma, quando se pensa no Celpe-Bras e no CELU como exames de proficiência, há que se pensar também no efeito retroativo de seus processos de avaliação. Quando um brasileiro vai se preparar para prestar o CELU ou quando um argentino o faz para prestar o Celpe-Bras, necessariamente, eles deverão pensar não apenas nas questões linguísticas inerentes à aquisição desses dois idiomas, mas ainda nas demandas de tarefas que pressupõem os construtos desses exames. Claramente, elas têm como princípio pedagógico avaliar o examinando, a fim de que se possa saber se ele é capaz de usar a língua alvo em situações do mundo real, contextualizadas. Nesse sentido, a avaliação assume um papel fundamental quando instiga e impulsiona o aprendiz a adquirir também uma competência intercultural da língua que está aprendendo, seja ela qual for.

Considerando-se a perspectiva da relevância das interações socioculturais no ensinoaprendizagem e na avaliação de segunda língua, a aplicação dos testes de proficiência acaba por merecer um olhar crítico e observador. De acordo com Diane Larsen-Freeman, em The Handbook of Language Teaching (2011), uma avaliação fora de contextos e fragmentada não dá conta de mensurar se o aluno seria capaz de poder usar a gramática na fala real ou na escrita, 
ou seja, contextualizada. A visão, a partir da qual se deve analisar a habilidade gramatical na interação com a habilidade pragmática, está diretamente relacionada à compreensão intercultural que se precisa ter, a fim de que a língua possa fazer sentido em situações de uso. Relativamente à questão da Dimensão Social, Larsen-Freeman aponta ainda para o fato de que a avaliação pautada pela visão social de performance não pode ser mais ignorada, sobretudo, no que diz respeito à relação avaliando-avaliador.

Tanto na preparação do aprendiz, quanto na execução das tarefas nos exames de proficiência, é preciso perceber a necessidade de se valorizar o aspecto intercultural, presente nesses dois testes de proficiência, no sentido de que é por meio dele que o aluno de segunda língua pode estar apto a se manifestar em um outro idioma de forma efetiva e funcional. Assim, ele não só será capaz de alcançar uma proficiência adequada, mas também se instrumentalizará para alcançar um nível de comunicação mais eficientemente no idioma pretendido. Segundo Pozzo, "resulta revisar la posibilidad de promover una consciencia intercultural en una instancia de evaluación, en tanto los aspectos procedimentales y actitudinales suelen ser los menos tenidos en cuenta, a pesar de su influencia en la forma de evaluar y ser evaluado ${ }^{5 "}$ (POZZO, 2008, p.1).

Como se pode perceber no Quadro Europeu Comum de Referência (QECR, 2001), a avaliação, nesses exames, também é empregada no sentido de avaliação de proficiência do utilizador da língua, de seu desempenho, de maneira que ele possa ser capaz de interagir e produzir em determinados contextos, tanto oralmente quanto na escrita. Seguindo essas premissas, tanto no Celpe-Bras quanto no CELU, é possível verificar que se busca avaliar os conhecimentos e capacidades que um candidato precisa ter para ser eficaz na sua atuação, abrangendo, além dos conhecimentos linguísticos, os contextos culturais da língua em questão.

Em ambos os exames, a avaliação ganha uma relevância profunda nessa perspectiva, pois, ao se preparar para as tarefas de cada um, o candidato será capaz de aprender estratégias comunicativas que poderão levá-lo a uma apreensão da língua para além de suas estruturas linguísticas. O âmbito relacional também será o foco da atenção e do estudo desses pretendentes. A relevância da interculturalidade no aprendizado de segunda língua passa a ser também uma questão de abordagem essencial para que se possa pressupor habilidades e competências em língua estrangeira. As estratégias de ensino-aprendizagem precisam tomar

\footnotetext{
${ }^{5}$ Tradução livre: resulta revisar a possibilidade de promover uma consciência intercultural em uma instância de avaliação, tanto nos aspectos procedimentais quanto nos atitudinais, que tendem a ser menos tidos em conta, apesar de sua influência sobre como avaliar e ser avaliado.
} 
uma direção mais abrangente, no sentido de se buscar não apenas a compreensão metalinguística do idioma estudado, mas também alcançar um empenho eficiente em tarefas comunicativas que possam integrar e potenciar as quatro habilidades pretendidas para se ter um nível avançado de proficiência no idioma que se pretende aprender.

\section{AS INTER-RELAÇÕES LINGUÍSTICAS E INTERCULTURAIS NOS DOIS EXAMES}

No âmbito das questões linguísticas, não é possível ater-se ao estudo de vocabulário e estruturas, quando se empreende aprender uma língua estrangeira. Um paradigma importante a ser vencido nesse sentido é o fato de que uma língua não deve ser tratada isoladamente de seu uso, muitas vezes, atrelado a determinadas contemporaneidades, demarcadas por seu lugar no tempo e no espaço. A questão da contextualização dos elementos provocadores no Celpe-Bras e nas tarefas do CELU encontra-se atrelada à visão de cultura e de significações que extrapolam os âmbitos gramatical e vocabular. Os elementos visuais dos dois testes trazem em si informações e contextos que, sem uma visão global de interculturalidade, fica difícil a um candidato de segunda língua apreender.

$\mathrm{Na}$ sequência, serão avaliadas duas tarefas, uma de cada exame, a fim de se verificar a relevância destas reflexões. (Vide anexos)

No Elemento Provocador número 13, do Celpe-Bras 2014/2, intitulado "Leite derramado", verifica-se uma expressão bem conhecida por parte da maioria dos brasileiros. Contudo, dependendo do contexto apresentado, escapa-se a um estrangeiro a real noção do que isso possa representar.

A foto apresentada é a de um copo de leite sobre uma superfície azul, suspenso no ar, em posição transversal, deixando escapar umas gotículas de leite para fora da borda. Acima, há a seguinte frase: "VIDA SIMPLES". Abaixo da imagem, vêm-se os seguintes textos: "Não adianta chorar o leite derramado", "Aprender com o que deu errado nos ajuda a fazer escolhas melhores e torna nossa vida muito mais leve e feliz".

No caso, as palavras chorar, leite e derramar imprimem à expressão que se quer trabalhar um contexto muito específico. Apesar disso, não há, na imagem, a materialidade do leite no chão, ou seja, derramado, nem alguém chorando pela tragédia de o ter deixado cair e, portanto, não conseguir recuperá-lo novamente. Quer dizer, se o estrangeiro não tem uma compreensão contextual dessa expressão e do uso adequado da ideia representada por ela, ele não conseguirá estabelecer relações entre o significado literal do acontecimento a uma situação 
específica de uso, metaforicamente. Uma expressão em Espanhol que pode aproximar-se dessa do Português seria a lo hecho, pecho que, apesar de traduzir uma ideia aproximada do que representaria "não chorar o leite derramado", não apresenta similitude vocabular ou linguística uma com a outra. Inclusive, pela foto, apenas com a imagem do copo de leite que está por cair não seria possível associar essa ideia ao fato de que não é possível ficar lamentando por algo que se perdeu ou que não deu certo e seguir em frente. Sendo assim, além de outros contextos possíveis, compreender expressões idiomáticas exige por parte de um estudante de segunda língua habilidades que transcendem as puramente linguísticas, pois, muitas vezes, estão associadas a gírias, jargões ou contextos culturais específicos que precisam ser também conhecidos e estudados.

Ademais das questões linguístico-contextuais descritas acima, em um material do CelpeBras, segue-se um exemplo de uma prova do CELU, Cuadernilllo de Actividaddes 4, Parte Escrita, pág. 3, no qual, para um brasileiro que está prestando tal exame, seria complicado aplicar uma proficiência adequada de Espanhol, sem que tenha um conhecimento básico da cultura mapuche e seu contexto sociocultural. No caso, o candidato escutará, duas vezes, um fragmento de um programa de rádio e deverá escrever uma carta de leitor ao diário da cidade, para denunciar os atos ocorridos, dando seu ponto de vista. O áudio trata de uma delação sobre a escavação em busca de água, em território habitado por comunidades mapuches, por parte de um grande proprietário de terras norte-americano. Essas regiões, denominadas Rewes, são terras sagradas dos mapuches há cerca de catorze mil anos.

Como se pode perceber, tanto em um quanto em outro exame, a questão linguística está intimamente atrelada à interculturalidade, sem a qual, mesmo que imbuído de uma competência estrutural a cerca do idioma estudado, não é possível um bom desempenho na língua estudada nesses testes de proficiência.

\section{CELPE-BRAS E CELU COMO INSTRUMENTOS DE INTERAÇÃO ENTRE BRASIL E ARGENTINA E ENTRE AMBOS E OS MUNDOS LUSÓFONO E HISPANÓFONO.}

Logo que as ideias de blocos econômicos e da globalização começaram a tomar conta das relações internacionais, começou-se a pensar no que seria uma dissolução territorial, mais especificamente em processos de desterritorialização. Contudo, esse mito foi cedendo lugar a uma outra dinâmica intitulada multiterritorialidade. Esse conceito, pesquisado por Haesbaert (2004) e aprofundado pelo próprio autor em textos subsequentes, é algo a se observar de forma 
muito peculiar, ao se pensar no Celpe-Bras e no CELU como exames de proficiência no Brasil e na Argentina.

Haesbaert (2005, pág. 6776) afirma que "a territorialidade, além de incorporar uma dimensão estritamente política, diz respeito também às relações econômicas e culturais". Nesse sentido, tanto ao se preparar para esses exames, quanto adquirindo resultados de proficiência capazes de promover a inserção do falante de segunda língua no país para o qual pretende atuar, é possível perceber, no caso de Brasil e Argentina, que, cada vez mais, há possibilidades de se ampliar nossa atuação em espaços diversos, sejam eles territoriais, sociais, culturais ou políticos. Obviamente, não se está referindo aqui à noção clássica e geográfica de território, mas, sim, à sua concepção abstrata e simbólica.

Essa ideia contemporânea de multiterritorialidade não é nova. O homem sempre buscou produzir e habitar mais de um território, fazer-se pertencer e inteirar-se com o outro, com a cultura do outro. Hoje, as relações entre nações e culturas estão cada vez mais entrelaçadas, inclusive no que diz respeito ao estudo e ao trabalho. É nesse sentido que o Celpe-Bras e o CELU imprimem um caráter de internacionalização da questão laboral, estudantil e até mesmo do lazer, no caso do turismo regular, aos que lhes prestam exames.

Brasil e Argentina são países fronteiriços e têm uma forte relação sócio-econômica e cultural que permite uma interação estreita entre ambos, contudo a certificação de proficiência em português-espanhol é capaz de promover não apenas uma relação multiterritorial que se restrinja a estas duas nações. Tanto a Língua Portuguesa quanto a Língua Espanhola refletem um universo interacional mais transcendente, para além das Américas. Há uma diversidade de territórios a dispor daqueles que, certificados com níveis de proficiência adequados, queiram intervir, vivenciar e experimentar múltiplas territorialidades em diversos continentes.

Segundo Haesbaert (2005, pág. 6791), "pensar multiterritorialmente é a única perspectiva para construir uma outra sociedade, ao mesmo tempo mais universalmente igualitária e mais multiculturalmente reconhecedora das diferenças humanas".

\section{CONSIDERAÇÕES FINAIS}

Pela análise de seus construtos, pode-se perceber que tanto o Celpe-Bras quanto o CELU têm uma visão de língua baseada em seu uso cotidiano e em situações de uso real. Esse entendimento pressupõe, necessariamente, uma compreensão bastante ampla do estudo de segunda língua, pois todas as avaliações destes exames de proficiência irão refletir uma 
realização de tarefas, cuja abordagem comunicativa estará focada na utilização da língua. O impacto dessa abordagem é considerável, se se pensar que todo candidato que se inscrever para ambos os testes irão se preparar para os exames a partir dessa perspectiva.

Dessa forma, baseando-se no pressuposto de que ambos os testes se alicerçam no uso do idioma em situações do dia a dia do falante, o peso que a cultura dos dois países, Brasil e Argentina, têm para os candidatos que intentam realizá-los é muito grande. Sempre que brasileiros e argentinos se preparam para as tarefas propostas por seus exames de proficiência e começam, para tanto, um processo de estudo e pesquisa, acabam não só se instrumentalizando para dominarem as estruturas linguísticas de referidos idiomas, mas também para se desbravarem em seus universos culturais.

Por meio dessa premissa intercultural, é possível perceber, portanto, que a mundialização atual favorece, sob o pano de fundo de um progresso sem precedentes das técnicas de comunicação, uma inserção muito segura a multinacionalidades. Não há diversidade política de convivência cultural se não houver, desde o início, o reconhecimento da diversidade linguística, e, no centro, a valorização das línguas maternas. Línguas românicas oferecem uma real visibilidade e constituem fatores de identidades coletivas. Segundo Wolton (2013), o Espanhol e o Português entram nesse contexto e representam uma vantagem incontestável para a América do Sul, onde esses idiomas são dominantes. O continente é um grande laboratório de diversidade cultural, com muito mais pontos em comum entre seus países que outras partes do mundo, e com menos conflitos e, das Américas a outras territorialidades, é um pequeno passo.

Partindo-se dessa perspectiva, verifica-se que os construtos do Celpe-Bras e do CELU proporcionam aos seus interessados não apenas uma testagem de conhecimentos linguísticos, mas também a possibilidade de acederem a uma pletora intercultural e multiterritorial que, certamente, se fará reconhecer.

\section{REFERÊNCIAS}

BARROSO, Silvina B. \& DANDREA, Fabio D. El abordaje de la pragmática sociocultural en la enseñanza de ELE y la literatura como herramienta metodológica para la reposición de contextos socioculturales. Buenos Aires, Coloquio CELU, 5 e 6 de agosto de 2011.

BRASIL. Ministério da Educação. Instituto Nacional de Estudos e Pesquisas Educacionais Anísio Teixeira. Certificado de proficiência em língua portuguesa para estrangeiros: elementos provocadores da parte oral. Brasília: MEC/INEP, 2014. Disponível em: 
http://www.ufrgs.br/acervocelpebras/arquivos/elementos-provocadores-da-parte-oral/2014_2 (Acessado em: 14 de janeiro de 2015)

BROWN, H. Douglas. Language Assessment: Principles and Classroom Practices. New York: Pearson/Longman, 2004.

CARVALHO, Simone da Costa. Políticas de promoção internacional da língua portuguesa: ações na América Latina. UFRGS, 2012.

CARVALHO, S.; SCHLATTER, M. (2011). Ações de difusão internacional da língua portuguesa. Cadernos do IL. Porto Alegre, no. 42, pp. 260-284.

CASSIANO, Ana Carolina. A Experiência Intercultural nas Escolas: um guia para educadores. AFS Intercultura Brasil. Rio de Janeiro, 2013.

CELU. Certificado Español como Lengua Extranjera. Disponible em: http://www.celu.edu.ar/sites/www.celu.edu.ar/files/Cuadernillo4.pdf

(Acessado em: 14 de janeiro de 2015)

DELIA, Leighton Gabriela. Evaluación e interculturalidad en zonas de vulnerabilidad social. Coloquio CELU, Santa Fé, 2008.

FARMHOUSE, Rosário. Revista B-i, Alta Comissária para a Imigração e Diálogo Intercultural - ACIDI. Lisboa. Edição 83, editorial, agosto de 2010.

HAESBAERT, Rogério. Da desterritorialização à multiterritorialidade. Anais do X Encontro de Geógrafos da América Latina - Universidade de São Paulo/ SP, 2005.

2004. O mito da desterritorialização: do "fim dos territórios" à multiterritorialidade. Rio de Janeiro: Bertrand Brasil.

LARSEN-FREEMAN, D. (2011). In LONG, Michael H.; DOUGHTY, Catherine J. The Handbook of Language Teaching, Oxford: Wiley-Blackell, 2011.

LONG, Michael H.; DOUGHTY, Catherine J. The Handbook of Language Teaching, Oxford: Wiley-Blackell, 2011.

MENDES, Edleise. Aprender língua, aprendendo cultura: uma proposta para o ensino de português língua estrangeira. In: CUNHA, Maria Jandira; SANTOS, Percília. (Org.). Tópicos em português língua estrangeira. Brasília-DF: Editora Universidade de Brasília, 2002, v., p. 185-199.

OLIVEIRA, Gilvan Müller de. Política linguística e internacionalização: a língua portuguesa no mundo globalizado do século XXI. Trabalhos em Linguística Aplicada (UNICAMP), v. 52, p. 409-433, 2013.

POZZO, María Isabel. Interculturalidad y evaluación en ELE: fundamentos teóricos y propuestas para su desarrollo en el aula. Coloquio CELU, Santa Fé, 2008. 
PRATI, Silva. La evaluación en Español lengua Extranjera. Elaboración de Exámenes. Ed. Libros de la Araucaria. Buenos Aires, 2007

PROTOCOLO ENTRE O MINISTÉRIO DA EDUCAÇÃO, CIÊNCIA E TECNOLOGIA DA REPÚBLICA ARGENTINA E O MINISTÉRIO DA EDUCAÇÃO DA REPÚBLICA FEDERATIVA DO BRASIL PARA A PROMOÇÃO DO ENSINO DO ESPANHOL E DO PORTUGUÊS COMO SEGUNDAS LÍNGUAS. Puerto Iguazú, 2005.

QUADRO EUROPEU COMUM DE REFERÊNCIA PARA AS LÍNGUAS - Aprendizagem, Ensino, Avaliação. Edição Portuguesa, Conselho da Europa, 2001.

RHODES Phd, Robert L. Assessing Culturally and Linguistically Diverse Students: A Practical Guide.

RODRIGUES, F. S. C.. La integración Brasil-Argentina alrededor del CELU. Consorcio Interuniversitario para la Evaluación de Conocimiento y Uso de ELE. In:http://www.celu.edu.ar/sites/www.celu.edu.ar/files/images/stories/pdf/coloquios/5 coloquio/ La_integracion_Brasil_Argentina_alrededor_del_celu_Dos_Santos_Castelano.pdf 2009.

(Acessado em 15 de dezembro de 2014)

SCARAMUCCI, M.V.R. Evaluacición de Proficiencia en Lengua Extranjera: Relaciones con la Enseñanza y Evaluacion de Rendimiento, 2003.

SCHLATTER, M., SCARAMUCCI, M., PRATI, S., \& ACUÑA, L. Celpe-Bras and CELU proficiency exams: implementation, characteristics and impacts of the exams on BrazilArgentina relations. In: http://www.celu.edu.ar/index.php?option=com content\&view=article\&id=62\&Itemid=67. A primeira versão deste artigo foi apresentada no Terceiro congresso Internacional de ALTE(Association of Language Testers in Europe), Cambridge, Inglaterra, en abril de 2008. (Acessado em 15 de dezembro de 2014)

WOLTON, Dominique. Mundialização, diversidade cultural, democracia. In: Pesquisas em didática de línguas estrangeiras - Grandes temas - BARROS, Maria Lúcia Jacob D. de; BARBOSA, Márcio Venício, ROCHEBOIS, Christianne Benatti. Organizadores Ed. Bilíngue.

- Belo Horizonte: Faculdade de Letras/UFMG, 2013

ZILLES, A.; CÁRCERE, G.; VILLAVICECIO, L. O Certificado de Español, Lengua y Uso (CELU): entre linguagem, avaliação e políticas linguísticas. Entrevista, 2014.

\section{OS AUTORES}

Fernanda Ricardo Campos é Mestre em Estudos de Linguagens pelo CEFET-MG (2016). Especialista em Leitura e Produção de Textos pela UFMG (2009). Graduada em Letras pela PUC-MG (2007). Foi professora do CEFET-MG, Leitora de Língua Portuguesa e Cultura Brasileira do MRE, na Universidade Nacional Mayor de São Marcos em Lima/Peru, 
colaboradora do Centro Cultural Brasil-Peru e do Setor Cultural da Embaixada do Brasil em Lima/Peru. Possui experiência na aplicação e correção do exame CELPE-BRAS. Integrante dos grupos de pesquisa Infortec e do Grupo de Pesquisa em Materiais e Recursos Didáticos, ambos do CEFET/MG. Atualmente é revisora de textos do Colégio Sagrado Coração de Maria-BH.

E-mail: nanda.ricardo@gmail.com

Ronaldo Tavares Gomes é Mestre em Estudos de Linguagens pelo CEFET-MG(2016). Possui graduação em Letras Espanhol pela Universidade Federal de Minas Gerais (1997) e graduação em Letras Português pela Universidade Federal de Minas Gerais (1993). Pós-graduado em Língua Portuguesa com Ênfase em Multiletramentos (2012) e em Metodologia do Ensino Superior (1997). Atualmente é professor do ensino básico, técnico e tecnológico federal no Colégio Militar de Belo Horizonte - $\mathrm{CMBH}$, atuando principalmente nos seguintes temas: aulas de Espanhol, letramento, projetos interdisciplinares, avaliações, ecologia, teatro, feira de ciências, arte e cultura.

E-mail:portenho01@gmail.com 
ANEXO 1 - Elemento Provocador 13, Interação Face a Face, 2014/2.

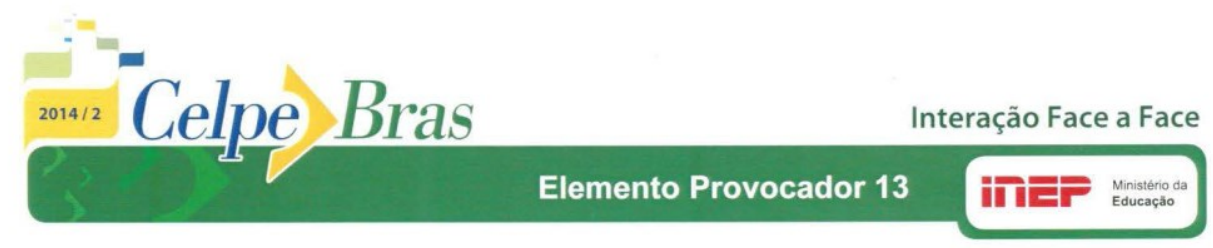

\section{Leite derramado}

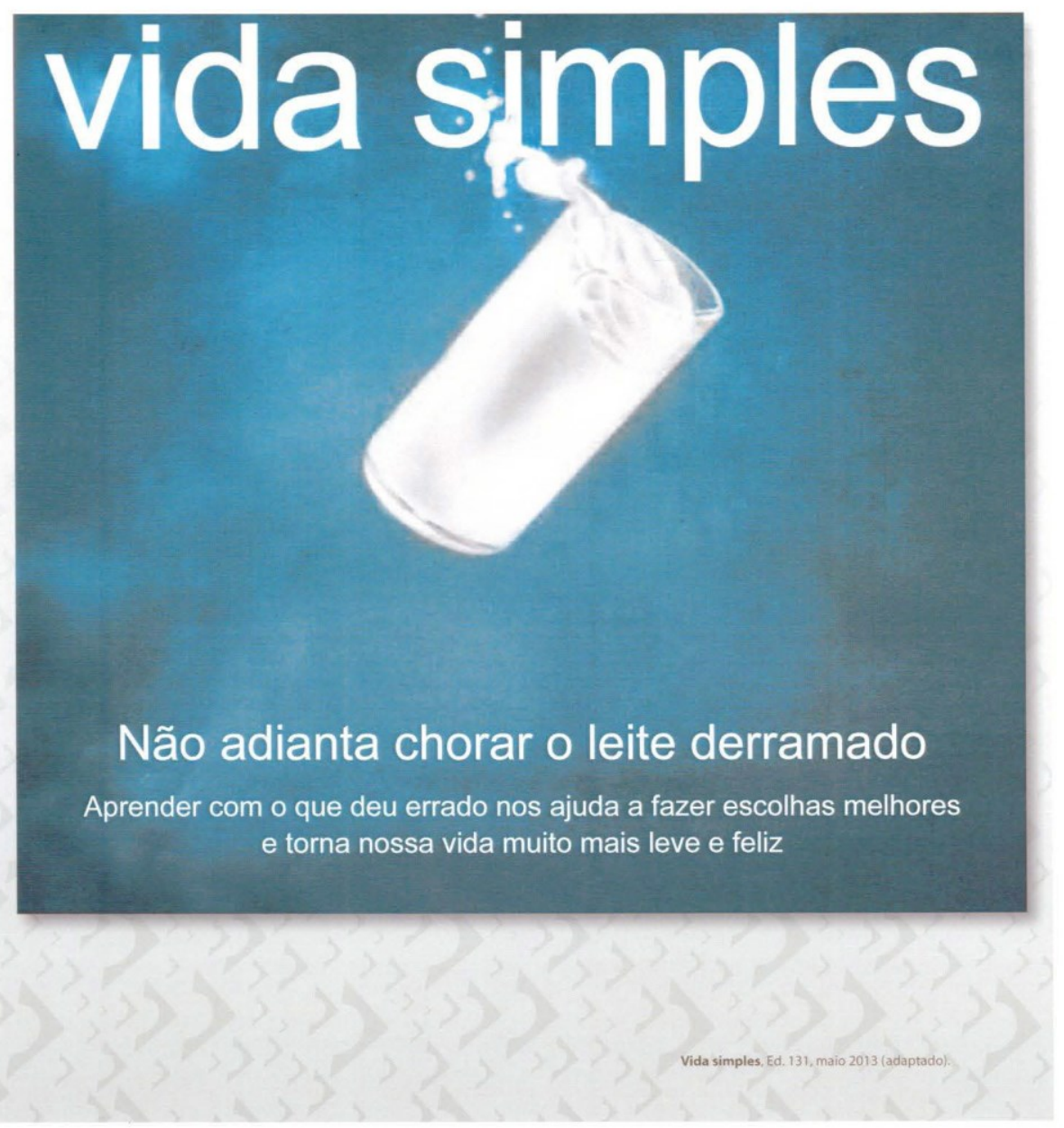

(Acessado em 14/01/2015) 
ANEXO 2 - Cuadernillo de actividades 4, Parte Escrita, pág. 3.

\section{Celu}

Certificado de Españo Lengua y Uso

\section{Investigación Nacional (Villa La Angostura)}

Usted escuchará el fragmento de un programa radial llamado "Investigación Nacional" (Argentina, 19/1/2010) que se pasará dos veces - click aquí para acceder al audio. En la página siguiente, usted tiene una hoja en blanco para tomar notas, si las necesita.

Usted vive en la zona de Villa La Angostura y escucha la siguiente noticia en la radio. Escriba una carta de lectores al diario de la ciudad para denunciar los hechos ocurridos recientemente en ese lugar y dar su punto de vista.
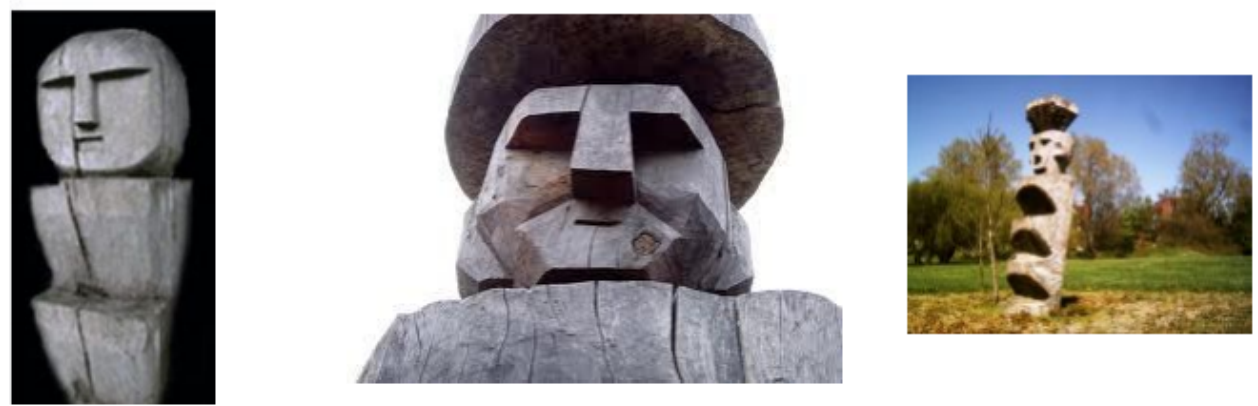

Rewes del pueblo mapuche. Uno de ellos se encuentra en Villa La Angostura

(Acessado em 14/01/2015) 